\title{
O Diagnóstico das Trombofilias
}

\author{
Ribeiro DD. ${ }^{1}$ \\ ${ }^{1}$ Belo Horizonte - Brasil. \\ E-mail: ddribeiro@terra.com.br
}

Ribeiro, D. D. 2013. O Diagnóstico das Trombofilias, p.45. In: Bastos, Francisco Reis. Anais do V Simpósio Internacional de Flebologia [Blucher Medical Proceedings n.1 v.1]. São Paulo: Blucher, 2014

http://dx.doi.org/10.5151/medpro-flebo-SIF_24
A trombose venosa é uma doença que ocorre em cerca de 1-2 por 1000 pessoas por ano. Apesar do tratamento adequado, até um quarto dos pacientes com trombose venosa experimentará um evento recorrente dentro dos próximos cinco anos. A presença de um fator de risco transitório ou reversível no momento da trombose venosa está associada a uma diminuição do risco de recorrência após o término da terapia anticoagulante. Portanto, um período relativamente curto de tratamento anticoagulante com antagonistas da vitamina $\mathrm{K}$ é recomendado para aqueles pacientes com fatores de risco para trombose venosa claramente identificados. Como um número significativo de primeiros eventos ocorre sem um fator de risco evidente (trombose idiopática), muitos pacientes necessitam de tratamento anticoagulante por tempo prolongado ou indeterminado, que poderia aumentar a incidência de efeitos adversos, sendo o mais temível, o sangramento grave. Identificar outros grupos de pacientes com baixo risco de recorrência que poderiam se beneficiar de tratamento anticoagulante por um período menor é um objetivo a ser perseguido, e a pesquisa das trombofilias é um potencial marcador na avaliação entre o risco e o beneficio da manutenção da anticoagulação.

Uma vez que as trombofilias identificadas através de exames laboratoriais podem estar presentes em até 50\% dos pacientes com trombose venosa, a identificação destas passou a fazer parte da avaliação dos pacientes após o primeiro evento trombótico. Os potenciais benefícios do diagnóstico laboratorial de trombofilia são a oportunidade para elucidar o fator associado à ocorrência da trombose e à possibilidade de orientar e acompanhar as pessoas assintomáticas da família afetada. Por outro lado, existem desvantagens na realização de testes para trombofilia. A maioria das trombofilias hereditárias associa-se a um baixo risco de recorrência após um primeiro episódio de trombose venosa, sendo, portanto extremamente questionável a pesquisa destas após um evento tromboembólico. No entanto, na prática clínica, estes testes são solicitados indiscriminadamente após o primeiro evento de trombose venosa. O desafio atual é tentar identificar o grupo de pacientes que realmente irão de beneficiar da realização dos exames para a pesquisa de trombofilias.

Palavras-chave: trombose venosa, trombofilia, tratamento da trombose, embolia. 